Braithwaite, editor of the " Retrospect of Medicine and Surgery."

Dr. Forbes returned thanks.

Mr. Braithwaite also acknowledged the toast. $\mathrm{He}$ alluded to the fact that two of the most widely circulated medical journals had originated in the provinces, and by members of their own Association, and, therefore, he thought they could not afford to be looked upon in the manner which in some quarters there appeared a disposition to view them. (Hear, hear.)

This was the last toast given.

Mr. Hey vacated the chair about half-past eleven $o^{\prime}$ clock, and the company immediately after broke up.

\section{POOR-LAW MEDICAL RELIEF.}

TO THE EDITORS OF THE PROVINCIAL MEDICAL JOURNAL.

Gentlemen,-You were pleased, in April last, to publish a request of mine, that the gentlemen employed under the Poor-law Amendment Act, in charge of the sick poor, would be so good as to send to me such information as might enable me to draw up a paper on, or a digest of, the grievances they suffered, and wished to have redressed; and I have to thank a great many for the readiness with which they complied with that request.

It is stated in the Ninth Annual Report of the Poor-law Commissioners, laid before Parliament in May last, that the duties of the union surgeons were much diminished in the North of England in consequence of the various dispensaries, \&c., which gave relief to the sick poor; and, from medical men being employed to take charge of poor persons engaged in collieries, factories, \&c., it became necessary to write to the surgeons of 112 unions on these points, which delayed the printing of my report, entitled "Facts and Observations relating to the Administration of Medical Relief to the Sick Poor in England and Wales," until the 27 th of June. This report was privately addressed to the members of the Commons House of Parliament, and I had the honor of sending a copy to you. The additional matter for inquiry, which the northern counties furnished, rendered it necessary to refer to some members of the House of Commons conversant with the affairs of collieries and factories, and Lord Ashley, who takes the deepest interest in the whole subject, finding, from the state of public business, that nothing could be done this session, gave notice, on Wednesday, the 26th, that he should move, early in the next session of Parliament, "for a select committee to inquire whether the seventh * resolution of the Report of the Committee on the Poor-laws, in August, 1838, has been carried into effect, and also into the whole mode and extent of administering medical relief to the poor."

This committee will, no doubt, be granted, and will be composed of gentlemen of the highest character and station in the House of Commons, at whose hands the sick poor and the medical profession may look for strict justice. I have promised Lord Ashley, and several of the gentlemen who have consented to be placed upon it, that not more than one week of their time shall be occupied in establishing all the points

- The seventh resolution recommends that the remuneration to the medical men should be such as to insure proper attention and the best medicines. at present claimed. I take the liberty of mentioning that it will be in all probability the last opportunity the members of the medical profession will have for a long time of maintaining their just rights, and those of the sick poor committed to their charge; and I hope they will take care that there is nothing that the committee ought to know which shall not be communicated to me by the commencement of the ensuing year. I shall be most happy to advise and confer with any individuals, societies, bodies, or associations, who will favor me with their assistance; and I beg that every one will be assured that $I$ have no object in view in laboring to effect the redress of the grievances which at present exist with respect to the sick poor, than the good which will result to them and to the medical profession from their removal. There are neither public nor private interests to serve in which I have any personal concern, nor with which I am acquainted.

I shall feel obliged by your inserting this letter in your Journal, and have the honor to be, Gentlemen, Your most obedient servant, G. J. Guthrie.

4, Berkeley-street, Berkeley-square, July 28, 1843.

\section{PILULA FERRI COMPOSITA.}

In order to prepare this pill in such a manner as to keep the carbonate of iron in an undecomposed state, and to insure uniform consistence of the mass, it has been found that the directions given in the Pharmacopœia will be sufficient for these purposes, if the following points be attended to:-Dissolve the sulphate of iron, finely powdered in the treacle, with a moderate heat, and add the carbonate of soda, stirring constantly until the effervescence has entirely ceased, and the mixture has become cool; then add the myrrh gradually, and incorporate the mass. As a little evaporation takes place at the commencement of the process, a small excess of treacle is requisite to supply the deficiency. This mass retains its color and consistence remarkably well.-Pharm. Journ.

\section{POISONING BY ARSENIC OF NINE PERSONS.}

SUCCESSFUL EMPLOYMENT OF THE HYDRATED SESQUIOXIDE OF IRON.

A case has recently been tried at a court of assize in France (Sarthe), in which a girl of nineteen was accuscd of having endeavoured to poison a whole family by mixing arsenic with their food. Nine persons dined on milk porridge; shortly after one of them felt indisposed, and left the table; a second soon experienced the same effect, and in a short space of time all of them were attacked with vomiting, sense of suffocation, and pains in the bowels. The vessel in which the food had been prepared was immediately examined, and its bottom found covered by a large quantity of thick white sediment, which proved to be arsenic. The hydrated sesquioxide of iron was energetically employed, and, although the quantity of arsenic taken had evidently been considerable, yet all eventually recovered by the empl oy ment of the antidote.-Gazette des Hopitaux. 